\title{
FEED ADDITIVES IN POULTRY
}

\author{
HADEEL M. HAMEED \\ Department of Physiology, Biochemistry and Pharmacology, College of Veterinary Medicine, \\ University of Mosul, Iraq.
}

Received: 29 December 2020; Accepted: 28 February 2021

\begin{abstract}
Poultry is an important source of animal protein, as it is considered an essential and effective pillar in filling an important part of the human nutritional needs. The poultry industry has made great progress in recent years and the productivity of poultry has increased significantly with high efficiency as a result of the progress and great efforts that have been made in applied research in various fields science of this industry. During recent years, attention has been paid to using plants with medicinal efficacy as alternates to antibiotics and growth improvement, mostly in the European Union, where antibiotics were banned in the diets of poultry flocks since 2006 due to concerns about increasing microbial resistance to the antibiotics used in poultry diets. The high costs and the possibility of developing microbial resistance to antibiotics has led to an urgent need to use another replacement to antibiotics in poultry feeding, such as the use of probiotics, organic acids, essential oils and phytogenic compounds with medicinal properties for the purpose of maintaining the health of poultry and obtaining the highest production in poultry flocks. The most common feed replacement used in poultry ration are antioxidants, antibacterial materials, enzymes, growth promoters and immune modulators, metabolites or substances that improve the $\mathrm{pH}$ and the internal environment of the intestine. Therefore, in this article, we will shed light on the most remarkable feed supplements used in poultry diets for the purpose of improving and increasing production efficiency in poultry field.
\end{abstract}

Keywords: feed additives, phytogenic compounds, poultry, antibiotics

\section{INTRODUCTION}

The rapid development in the poultry industry and the improvement of the production efficiency have led to an increase in the use of feed supplements, which have become widely available in poultry diets for many years. The poultry industry tends to elevate the output of eggs and meat, but

Corresponding author: Hadeel M. Hameed

E-mail address: dochadeel1979@gmail.com

Present address: Department of Physiology, Biochemistry and Pharmacology, College of Veterinary Medicine, University of Mosul, Iraq. while preserving the health of the animal and the consumer. The use of antibiotics in avian rations for the purpose of stimulating growth is useful in improving production and preventing infections but the excessive use of these antibiotics led to raise in bacterial resistance to diseases in addition to the accumulation of remnants of these drugs in animal products and therefore they were dispensed (Nisha, 2008). The elimination of antibiotics utilize as evolution stimuli in poultry ration led to the emergence of pathogens with economic losses in poultry farms. Therefore, the search for plant extracts with medicinal properties was 
directed to be included in avian diet as growth stimuli (Alloui et al., 2013). The component of the active materials in these compounds varies heavily related to the plant portion used (leaves, roots, flowers and buds), the geographical origin and the harvest season (Windisch et al., 2008). The use of supplements is subject to certain criteria, as these additives are applied in healthy animal farms for the purposes of feeding and improving production, unlike veterinary drugs that are used in the pathological case under veterinary surveillance for a restricted period and followed by a limited expectation time (EFSA., 2006). The nutritional benefit of the raw substance available to feed poultry flocks is restrict related to the size and quality of the microflora of the gut of the host bird and its ambience, avian do not possess microbiota able of destroying all nutrients, as these birds are distinguishes by limited immunity to resist infectious diseases due to the concentration of pathogenic microorganisms (Yegani and Korver., 2013). Studies have showed that, antibiotic alternatives (prebiotics, probiotics, enzymes, organic acids, external emulsifiers) have some positive regulatory and antioxidant effects of intestinal flora in poultry production, and these compounds can be considered as growth stimuli if their therapeutic and toxic effects are evaluated in addition to its interaction with drugs (Jatinder et al., 2020).

Preserving the health of the animal and the consumer. The use of antibiotics in avian rations for the purpose of stimulating growth is useful in improving production and preventing infections but the excessive use of these antibiotics led to raise in bacterial resistance to diseases in addition to the accumulation of remnants of these drugs in animal products and therefore they were dispensed (Nisha., 2008). The elimination of antibiotics utilize as evolution stimuli in poultry ration led to the emergence of pathogens with economic losses in poultry farms. Therefore, the search for plant extracts with medicinal properties was directed to be included in avian diet as growth stimuli (Alloui et al., 2013). The component of the active materials in these compounds varies heavily related to the plant portion used (leaves, roots, flowers and buds), the geographical origin and the harvest season (Windisch et al., 2008). The use of supplements is subject to certain criteria, as these additives are applied in healthy animal farms for the purposes of feeding and improving production, unlike veterinary drugs that are used in the pathological case under veterinary surveillance for a restricted period and followed by a limited expectation time (EFSA., 2006). The nutritional benefit of the raw substance available to feed poultry flocks is restrict related to the size and quality of the microflora of the gut of the host bird and its ambience, avian do not possess microbiota able of destroying all nutrients, as these birds are distinguishes by limited immunity to resist infectious diseases due to the concentration of pathogenic microorganisms (Yegani and Korver., 2013). Studies have showed that, antibiotic alternatives (prebiotics, probiotics, enzymes, organic acids, external emulsifiers) have some positive regulatory and antioxidant effects of intestinal flora in poultry production, and these compounds can be considered as growth stimuli if their therapeutic and toxic effects are evaluated in addition to its interaction with drugs (Jatinder et al., 2020).

\section{Phytogenic compounds}

Phytogenic compounds are natural compounds with biological properties derived from plants that have favorable influence on the health and growth of avians (Windisch et al., 2008), and are considered a modern class of feed additives that have received widespread interest in the chickens industry (Abd $\mathrm{El}-$ Hack et al., 2016). Plants and herbal extracts contain many bioactive substance like alkaloids, flavonoids, soaps, phenolic substances and polypeptides (Al-Yasiry and Kiczorowska, 2016). The mechanism of action of these compounds was different due to the multiplicity of their types as they have antibacterial effects, immune stimuli, antioxidants and growth stimuli (Abd El-Hack and Alagawany, 2015).

\section{Antioxidant effect of phytogenic compounds}

The antioxidant effect of phytogenic compounds was closely related to the essential oils present in these compounds (Alagawany et al., 2016), which leads to an improvement 
in the physiological performance of birds, food conversion ratio, safety and quality of meat (Dhama et al., 2015). It was also noted that, the addition of essential oils to avian ration led to an elevated in production of egg with improvement in physiological performance (Bozkurt et al., 2009). The need to use natural antioxidants has become necessary due to their importance in reducing oxidative stress and many diseases (Kim et al., 2015). The antioxidant effect of these materials was due to their free radical scavenging role in the addition to increasing the level of glutathione and catalase and reducing the level of malondialdehyde (Bharavi et al., 2010). Where Labaque et al. (2013) showed that, the administration of thyme at a dose of $80 \mathrm{mg} /$ bird / day led to an improvement in the productive characteristics of the quails subjected to stress. Inaddition Safa (2014) showed that adding a blend of hot red pepper and black pepper at different concentrations to the ration of broiler increased the percentage of dressing percentage. In related study, Abdel-Wareth and Lohakare (2014) indicated that the addition of mint leaves at a concentration of 5, 10,15 and $20 \mathrm{~g} / \mathrm{kg}$ feed for 12 weeks in laying hens' diets at 64 weeks of age led to raised in the production, weight and mass of eggs. Cho et al. (2014) stated that adding thyme to broiler ration at a concentration of $259 \mathrm{mg} / \mathrm{kg}$ of feed resulted in a significant decrease in the numbers of Salmonella and E. coli in the gastrointestinal tract.
Influence of phytogenic compounds on nutrient digestion and make up the digestive system

Many herbs and medicinal plants have multiple effects on the gastro-intestinal tract, including anticolic and laxative, as it was observed that preparing broiler ration with mint at a concentration of $200 \mathrm{mg} / \mathrm{kg}$ led to an increased in protein digestion (Emami et al., 2012). Several studies indicated that, thyme, cinnamon, black pepper, ginger, red pepper and oregano in different concentrations had positive effects on the digestion and absorption of many materials with an improvement in the morphology of the gastrointestinal tract in broilers (Upadhaya et al., 2016). The positive effect of medicinal plants can be attributed to improving nutrient absorption as a result of stimulating saliva and bile secretion and increasing the effectiveness of digestive enzymes (Jag et al., 2007), leads to an improvement in the health of the bird in general. Maty and Hassan (2020) indicated that, the supplement of essential oils of thyme and activated charcoal at concentrations of 300, 600 and $900 \mathrm{~g} /$ ton feed to quail diets resulted in an elevated in villi length, villi width, crypts width and surface area of villi with an increased in the level of growth hormone. Kiczorowska et al. (2016) found that the addition of Boswellia Serrate at a concentration of 2 and $2.5 \%$ to a broiler diets led to a significant raise in the length of the duodenum and the gut as a whole.

\section{Diagram show benefit of feed additives in poultry (Gerhard, 2018)}

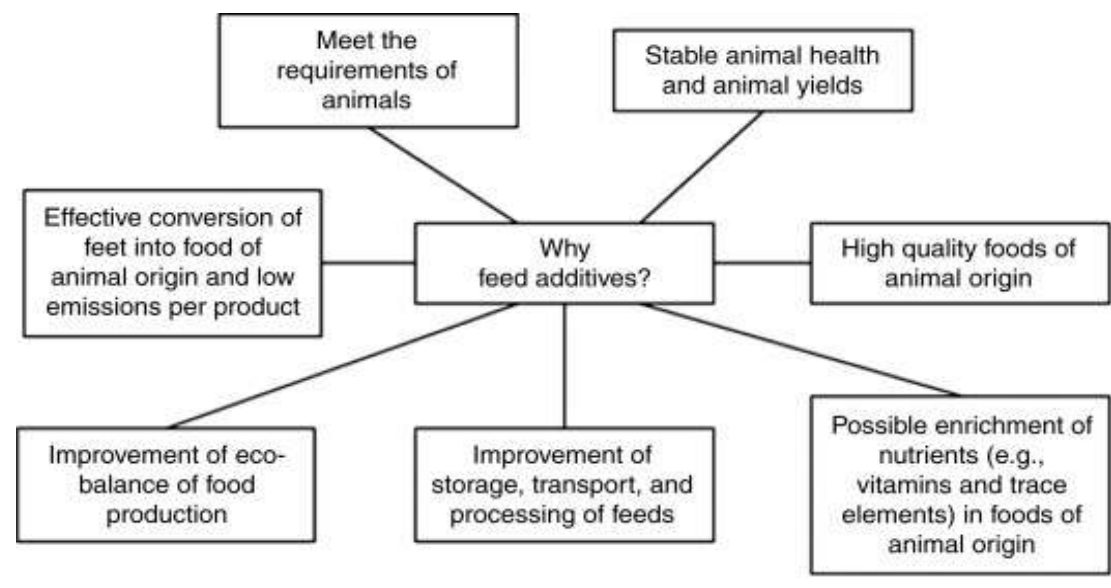


Prebiotic, Probiotic and Synbiotic as feed additives

Prebiotic

Prebiotics can be defined as selective fermentable substances allowed for change in composition and activity of microorganisms in the gut of the poultry and thus improve the health of the bird (Pineiro et al., 2008). Anther definition of prebiotic that are compounds used selectively by microbiota to improved bird performance (Gibson et al., 2017). Prebiotics include various non-starch polysaccharides including mannanoligosaccharide (MOS), maltooligosaccharide, gluco-oligosaccharide, xylooligosaccharide, lactulose, lactitol, etc. Prebiotic is a specific type of nutrient fiber that is unaffected by environment condition, and stomach acids that stimulate growth (Nagpal and Kaur, 2011). The prebiotic not only induced change in the activity of the intestinal microorganisms but also diverts fluids in and into the lumen of the gut (Arturo et al., 2019). The expected mechanism of action for prebiotic includes blocking of receptor portion for bacterial adhesion, modulation of immunity, produced of antibacterial compounds, increased exudation in the lumen of the intestine in addition to the induced of morphological change in intestinal structure (Pourabedin and Zhao., 2015). The immune modulation mechanism by the prebiotic was attributed to the stimulation of humoral immunity through the interaction of sugar with specific receptors located on the roof of macrophages and dendritic cells, which subsequently induced cytokine release and lymphocyte proliferation (Saad et al., 2013). Many prebiotics needed by about $3 \mathrm{~g} /$ day or more to showed their action (Roberfroid et al., 2017) and any product used at a lower dose than the aforementioned was not called a prebiotic unless it is demonstrated that the lower dose showed positive effects in increased the productive characteristics of the poultry (Gibson et al., 2017). Calik and Ergün (2015) indicated that, the use of Lactulose, which is a synthetic non-digestible sugar showed prebiotic effects in broiler leading to significant improvement in body weight, nutritional conversion ratio, increased in villi length and width and goblet cell numbers. Studies have showed that oligosaccharides of mannose or fructose possess an inhibitory effect on Salmonella and E-coli (Stanly et al., 2014). There are several characteristics that must be taken into consideration when selecting prebiotic as feed additives in poultry diets, including its resistance to stomach acids, intestinal catalyzing enzymes and the ability to be absorbed through the intestinal mucosa (Pourabedin and Zhao, 2015). In addition to the importance of the prebiotic in improving the effectiveness of the poultry digestive system, the prebiotic should work to create a barrier for colonies of pathogenic bacteria such as Campylobacter and Salmonella, and the importance of the prebiotic in increasing the effectiveness of production of short-chain fatty acids against pathogens produced by food (Kim et al., 2019). Another form of prebiotics such as MOS have a direct effect as an antigen and are able to increase the immune response (Teng and Kim, 2018). In general, the prebiotic fermented by healthy bacteria in the gastrointestinal tract produced lactic acid and short chain fatty acids in addition to some antibacterial compounds such as bacteriocin against different types of pathogens (Lavelle $e t$ al., 2010). The production of these materials is considered beneficial not only to lose the effectiveness of the microorganisms present in the gut, but also to improve the integration of epithelial cells in the intestine and thus lead to an raise in the assimilation of digested nutrients, which results in the improvement of the productive characteristics of the bird (Lan et al., 2005). The microorganisms in the gastrointestinal tract were affected by several factors including nutrition, gender, the surrounding environment in addition to the age of the chicken, these factors can change the types of bacteria present in the intestine, for example, Clostridiaeae and Enterobacteriaceae bacteria were considered among the main bacteria present in the intestine of the bird at the age of 7 days, while Lactobacillaceae and Clostridiacea represent the main bacteria at 35 days old in the bird's intestine (Pourabedin and Zhao.,2015). Studies showed that adding MOS from 0,5 to $0,8 \%$ to poultry diets led to a changed in the contents of the cecum by increasing the numbers of anaerobic bacteria (Lactobacillus and Bifidobacterium), and reducing the amount of Salmonella, E. coli and Clostridium perfringens (Corrigan et al., 
2015). MOS increased the villi length, the surface area of the villi, and decreased the depth of the crypts with an raised in the numeral of goblet cell (Rajani et al., 2016).

\section{Probiotic}

The probiotic is known as a microorganism that aids the growth of other useful bacteria in the intestine that get better the microbial balance of the gut (Hill, 2014). There are different sources of the probiotic including milk and fermented foodstuffs, in addition to the possibility of commercially isolating the probiotic from the fermented compounds of Lactobacillus and Bifidobacterium (Ran et al., 2019), in addition some types of fungi including strains of yeasts pertinence to Saccharomyces cerevisiae and Kluyveromyces (Anadon et al., 2016a). One of the good characteristics of the probiotic is that withstand handling and storage operations, resistant to gastric acidity, possesses the ability to adhere to the intestinal epithelium and potential for immune modulation (Anadon et al., 2016b). Among the mechanisms possessed by the probiotic are the so-called biostimulators of the intestinal microflora by increasing the production of antibodies and reducing cell apoptosis (Khan et al., 2016). The probiotic stimulates the production of mucin in the intestine by the goblet cells, which in turn prevents pathogenic bacteria from attaching to the walls of the gut (Hardy et al., 2013). Sohail et al. (2010) indicated that, the probiotic consisting of different types of lactobacilli possesses the ability to produce multiple types of enzymes, including amylase, keratinase and $\beta$-mannanase when added to the ration of broilers exposed to heat stress, which leads to improvement of many productive performance. Hameed et al. (2020) reported that adding the probiotic formed from Saccharomyces cerevisiae to quail diets at a concentration of $0.5 \mathrm{~g} / \mathrm{kg}$ of diet led to an increased in body weight, improved food conversion ratio with improvement in productive and reproductive characteristics through an increased in FSH and LH levels, AbouKassem et al. (2020) found that supplying poultry diets with $B$. toyonensis and $B$. bifidum delays the growth and reproduction of fungi in the gut. The addition of lactic acid producing bacteria as a probiotic to poultry ration increased villi length in the gut and villi width in the duodenum and improved gene code for mucin production (Ariyadi and harimurti., 2015). AbdelMoneim et al. (2019) and Abd El-Moneim et al. (2020) indicated that supplementation of Bifidobacteria strains to an 18 day old resulted in an increased in villi length in the hatched chicks. B. subtilis strains improved the bird's health and the food conversion ratio and increased the production of $\operatorname{IgA}$ in the duodenum when added to the poultry diet (Amerah et al., 2013). Addition of the probiotic containing the $B$. licheniformis strain at a dose of $250,500,750 \mathrm{mg} / \mathrm{kg}$ ration resulted in an increased in egg production in Laying hens (Chaucheyras-Durand and Durand, 2010). Abdullah (2014) reported that adding the probiotic supplement to pigeon food at a rate of $2 \mathrm{~g} / \mathrm{kg}$ of feed elevated body weight, red blood cell count and hemoglobin concentration. Fig (1).

\section{Fig (1) Mechanism of probiotic action (Daniel et al., 2019)}

1- Inhibition of pathogenic adhesion

2- Competitive exclusion

3- Immunomodulation

4- Reduce of toxin bioavailability

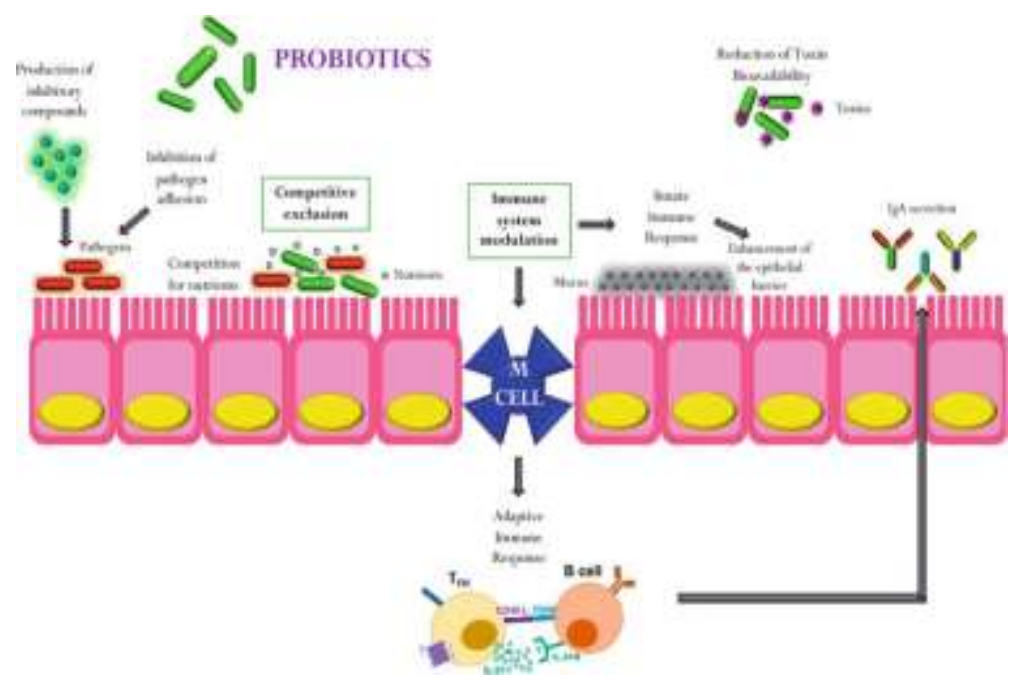




\section{Synbiotic}

Synbiotic is a combination of prebiotic with probiotic (Alloui et al., 2013). Among the types of probiotic used in synbiotic are Lacbobacilli, Bifidobacteria spp, S. boulardii, $B$. coagulans and others, while the prebiotic is oligosaccharides like fructooligosaccharide (FOS), xyloseoligosaccharide (XOS), inulin. The importance of synbiotic to host is to induced balance of intestinal microbiota, improved liver function and increased immune response (Zhang et al., 2010). Yitbarek et al. (2015) indicated that utilize a mixture of yeasts derived from carbohydrates with the probiotic to poultry diets led to an raised in body mass with an ameliorate on in the FCR.

\section{External enzymes as feed additive}

One of the important strategies in the poultry diet is the employ of external enzymes as nutrient supplements in their ration. There are different types of enzymes used in poultry diets, including pectinase, hemicellulase glucanase, phytase, xylanase and mannanase (Taylor-Pickard and Spring, 2008). Enzymes can be defined as biological analyzers that perform many vital functions in living organisms. It is found naturally in living organisms and is produced largely in aerobic and anaerobic cultures as well as fungi (Muhammad et al., 2010). The mode of action of these enzymes is generally summed up as follows:

1- A complete breakdown of plant cell walls containing anti-nutritional agents present in many feedstuffs used in animal diets by making a hole in the walls of these cells, allowing water and digestive enzymes to enter the interior and thus facilitate the digestion of starch and protein (Jakson et al., 2004).

2- Reducing the viscosity of digested materials as studies conducted on single stomach animals showed a decrease in the viscosity of digested materials due to enzymes that destroy non-starch polysaccharides (Cowieson et al., 2006).

3- Analyzing specific types of bonds for protein and carbohydrates, thus increasing the availability of amino acids and monosaccharaides (Meng et al., 2005).
4-Stimulating microflora colonies, as adding enzymes that destroy non-starch polysaccharides breaks down carbohydrate cell walls, reduced chain length and produced shorter chains that later become raw materials for fermentation of beneficial bacteria, Many research indicated that the addition of exogenous enzymes significantly changed volatile fatty acid production and colonies of microflora (Cheng et al., 2014).

5- Breaking down the chemical bonds in the primary foodstuffs that are not analyzed by the gastric enzymes in the digestive system, thus providing many nutrients for other enzymatic reactions (Elijah et al., 2013).

Choct (2006) indicated the crucial function of enzymes in the digestion of many nutrients, for example amylase digests starch, protease digests protein and lipase digests fats. Poultry, including broiler lack the enzymes that digest the fiber in the grains, so it needs some external enzymes to complete the digestion of foodstuffs, as these fibers work to prevent internal enzymes from binding to nutrients and thus get hindered in the digestion and absorption process, so adding grains frequently to poultry diets hinder the digestion process, increased the activity of unwanted microbiota in the intestine, reduced metabolism and inhibited growth and the quality of meat (Muhammad et al., 2010), so, adding enzymes to poultry diets reduced these negative effects of fiber (Choct, 2006). Exogenous enzymes can break down nonstarch polysaccharides in poultry that are fed sticky grains such as wheat and barley (Adebiyi et al., 2010). Preparing poultry diets with a mixture of glucanase and xylanase improved the FCR and nutrient digestion in the ileum, so, adding two types of enzymes produces a synergistic effect than if only one type of enzyme was used (Cowieson et al., 2010). Non-starch polysaccharides work by combining with water molecules in large quantities resulted in an increase in the viscosity of foodstuffs, which leads to problems in digesting carbohydrates, proteins and fats in the small intestine, the anti-nutrient effect of these sugars works to impede growth and food conversion ratio(Kalantra et al., 2017). Improving the digestion of nutrients by 
enzymes was by reducing the excretion of beneficial compounds, especially nitrogen, phosphorous, zinc and copper (Abd El-Hack et al., 2017). When adding enzymes to poultry diets that contain a high percentage of highfiber soybeans, it stimulated the digestive process and reduced the harmful effect of fiber (Alagawany et al., 2015). Enzymes also increased the energy level and protein digestion of broilers (Pourreza et al., 2007). The xylenase enzyme reduced the competition of pathogenic bacteria with intestinal microorganisms for food sources and this provided many beneficial nutrients to the bird (Hosseini and Afshar, 2017).

\section{External emulsifiers as feed additive}

The use of animal fats and vegetable oils has become an important strategy in poultry diets, especially in broiler, for the purpose of improving the growth rate and the food conversion ratio as a result of the high energy resulting from the assimilation of fats (Zhang et al., 2011). An emulsifier is defined as a mixture of two or more liquid substances that usually cannot be mixed together in which one of the liquids is scattered or widely diffused in the other liquid, and it is also known as a molecule with a hydrophilic and lipophilic part having this property in one molecule It gives it unique properties so that the emulsion can dissolve in fat and water and help mix these two parts (Siyla et al., 2017). Emulsifiers that are used naturally in the food industry are classified into two groups, the first is called natural emulsifiers such as bile salts, and the second is nutrient emulsifiers such as lecithin and Lysolecithin. The emulsification process rely on the nature of the fats and is mainly determined by the length of the chain, the location of phospholipids in triglycerides and the degree of saturation of fats $(\mathrm{Gu}$ and Li., 2003). The digestion of fats is complicated and required adequate amounts of bile salts and the lipase enzyme, which are essential for fat emulsification (Ravindran et al., 2016). The difficulty in digesting fats comes as it occur in the aquatic surroundings of the digestive system even though they are insoluble compounds in water and lipid assimilation was limited in young birds because of their reduced ability to make and excrete bile salts and the lipase till the digestive system matures in birds of age (10-14) day (Upadhaya et al., 2018). Several studies indicated that the supplement of external emulsifiers in the poultry diet improves fat digestion, growth rate and production (Zafarian et al., 2015; Zhao et al., 2015). There were many form of external emulsifiers that are used in chicken diets, including sodiumstearoy 1-2-lactylate (SSL), 1,3-Diacylglycerol, lysophospholipids, lysophosphatidylcholine, soybean oil, lecithin and Lysolecithin (Upadhaya et al., 2016). Tancharoenrat et al. (2013) also indicated that poultry showed the best growth and weight gain during the growth phase when adding vegetable oils to their diets, Kamran (2020) also indicated that using different types of fats and oils to broiler diets such as polyglycerol polyricinoleate and soybean oil at a dose of $0.25 \%$ and $0.45 \%$, respectively, improved the digestion of fats and the food conversion ratio with an increase in body weight. Emulsifiers increased the stimulation of micelles, increased the monoglycerid in the gut, expedited the transmit of nutrients through the walls of the intestine and allow for better absorption of digested substances and the preparation of energy (Roy et al., 2010). Emulsifiers also facilitated the process of shunting of fats and reduced their deposition in the liver, improved the absorption of calcium and phosphorus, it reduced the excretion of fats and increased the digestion of fats in the ileum (Dierick and Decuypere, 2004). The addition of fats to poultry diets was of great importance as it played an remarkable role in the assimilation of fat-soluble vitamins through their function as carriers (Iqdal and Hussain, 2009). The mechanism of action of food emulsifiers was to digest fats in three ways which is the formation of emulsion droplets, stimulating the formation of micelles, which are a complex of lipids-bile salts, and increasing the rate of monoglycerid in the intestine, this emulsification property allowed providing a greater surface area for the lipase to work more efficiently (Roy et al., 2010). Siyal et al. (2017) indicated that adding lecithin to the diets of broiler at a dose of $0.05 \%$ led to a declined in the level of cholesterol and LDL in the blood serum and a reduction of stress by lowering the level of MDA and thus improving the body weight and 
food conversion ratio in broilers. As mentioned by Aleksander et al. (2019) that adding external emulsifiers at concentrations of $250,500 \mathrm{ppm}$ to turkey diets from the age of 8 weeks to 16 weeks led to increased growth and improved fat digestion, so adding external emulsifiers to poultry diets has great importance in improving the characteristics bird productivity.

\section{CONCLUSION}

This article concludes that the use of feed additives as alternatives to antibiotics has a very important effect in improving the productive traits of birds due to their antibacterial properties, antioxidant and growth stimulator in addition to their importance to induce morphological changes in the structure of the gastrointestinal tract.

\section{REFERENCES}

Abd El-Hack, M.; Alagawany, M.; Farag, M.; Tiwari, R.; Karthik, K.; Dhama, K.; Zoriehzahra, J. and Adel, M. (2016): Beneficial impacts of thymol essential oil on health and production of animals, fish and poultry: A review. J Essen Oil Res. 28: 365-382. .https://doi.org/ 10.1080/10412905.2016.1153002

Abd El-Hack, ME. (2015): Alagawany Performance, egg quality, blood profle, immunefunction, and antioxidant enzyme activities in laying hens fed diets with thyme powder. J. Anim.Feed Sci., 24: 127-133.2015.https://doi.org /10.22358/jafs/65638/2015

Abd El-Hack, ME.; Chaudhry, MT.; Mahrose, KM.; Noreldin, A.; Eman, $M$. and Algawany, M. (2017): The efficacy of using exogenous enzymes cocktail on production, egg quality, egg nutrients and blood metabolites of laying hens fed distiller's dried grains with soluble. J. Anim. Physiol. Anim. Nutr. . doi: 10.1111/jpn.12825.

Abdel-Moneim, A.M.E.; Selim, D.A.; Basuony, H.A.; Sabic, E.M.; Saleh, AA. and Ebeid, TA. (2020): Effect of dietary supplementation of Bacillus subtilis spores on growth performance, oxidative status and digestive enzyme activities in
Japanese quail birds. Tropical Animal Health and Production, 52(2), 671680.2020. https://doi.org/10.1007/ s11250-019-02055-1

Abdel-Moneim, AE.; Elbaz, AM.; Khidr, RE. and Badri, FB. (2019): Effect of in ovo inoculation of Bifidobacterium spp. on growth performance, thyroid activity, ileum histomorphometry and microbial enumeration of broilers. Probiotics and Antimicrobial Proteins. 12(3), 873882.2019. https://doi.org/10.1007/ s12602-019-09613-xin press.

Abdel-Wareth, A.A.A. and Lohakare, J.D. (2014): Effect of dietary supplementation of peppermint on performance, egg quality, and serum metabolic profle of Hy-Line Brown hens during the late laying period. Anim. Feed Sci. Technol., 197: 114-120.2014. https://doi.org/10.1016/j.anifeedsci.2014 .07 .007

Abdullah, S.TH. (2014): Effect of probiotics addition into diet and drinking water in Collared Dove (Streptopelia decaocto) on certain physiological and biochemical parameters. raqi Journal of Veterinary Sciences volume 28 (2):127131.2014. https://doi.org/10.33899/ ijvs.2014.116920

Abou-Kassem, D.; Elsadek, M.; AbdelMoneim, A.; Mahgoub, S.; Elaraby, G.; Taha, A.; Elshafie, M.M.; Alkhawtani, D.M.; Abd El-Hack, M.E. and Ashour, E. (2020): Growth, carcass characteristics, meat quality and microbial aspects of growing quail fed diets enriched with two different types of probiotics (Bacillus toyonensis and Bifidobacterium bifidum). Poultry Science 2020. https://doi.org/10.1016/ j.psj.2020.04.019in press.

Adebiyi, OA.; Ologhobo, A.D.; Adu, O.A. and Olasehinde, T.O. (2010): Evaluation of the nutritional potentials of physically treated cowpea seed hulls in poultry feed. Emir.J.Food Agric. 22:232239.2010. https://doi.org/10.9755/ejfa. v22i3.4893

Alagawany, M.; Ali Ashour, E. and Reda, FM. (2015): Effect of dietary supplementation of garlic (Allium sativum) and turmeric (Curcuma longa) 
on growth performance, carcass traits, blood profle and oxidative status in growing rabbit. Ann Anim Sci.16: 489505.2016 https://doi.org/10.1515/aoas2015-0079

Alagawany, M.; Farag, MR.; Abd El-Hack, ME. and Dhama, K. (2015): The practical application of sunflower meal in poultry nutrition. Adv. Anim Vet Sci.3: 634-648.2015. https://doi.org/ 10.14737/journal.aavs/2015/3.12.634.64 $\underline{8}$

Aleksandra Drażbo1; Krzysztof Kozłowskil and Evi Croes (2018): The effect of emulsifier on growth performance and fat digestibility in Turkeys. Ann. Anim. Sci. 19 (2) 421-431.2019. DOI: 10.2478/aoas-2018-0055.

Alloui, MN.; Szczurek, W. and Świątkiewicz, $S$. (2013): The usefulness of prebiotics and probiotics in modern poultry nutrition. Ann Anim Sci. 13(1): 17-32 .2013.https://doi.org/10.2478/v10220$\underline{012-0055}$

Al-Yasiry, A.R.M. and Kiczorowska, B. (2016): Frankincense - therapeutic properties. Poct Hig MedDosw.70:380-391.2016. https://doi.org/10.5604/17322693.12005 53

Amerah, A.M.; Quiles, A.; Medel, P.; Sánchez, J.; Lehtinen, M.J. and Gracia, M.I. (2013): Effect of pelleting temperature and probiotic supplementation on growth performance and immune function of broilers fed maize/soy-based diets. Animal Feed Science and Technology, 180, 55-63.2013. https://doi.org/10.1016/j.anifeedsci.2013 .01 .002

Anadón, A.; Martínez-Larrañaga, MR. and Aresi, MMA. (2016b): Prebiotics: safety and toxicity considerations. In: Gupta RC (ed) Nutraceuticals: efficacy, safety and toxicity. Academic, Amsterdam, 757-775.2016.https://doi.org/10.1016 /b978-0-12-802147-7.00054-1

Anadón, A.; Martínez-Larrañaga, MR.; Arés, I. and Martínez, MA. (2016a): Prebiotics and probiotics: an assessment of their safety and health benefits. In: Ross Watson R, Preedy VR (eds) Probiotics, prebiotics, and synbiotics. Bioactive foods in promoting health: probiotics and prebiotics. Academic, San Diego, CA,3-23.2016. https://doi.org/10.1016 /b978-0-12-802189-7.00001-0

Ariyadi, B. and Harimurti, S. (2015): Effect of indigenous probiotics lactic acid bacteria on the small intestinal histology structure and the expression of mucins in the ileum of broiler chickens. International Journal of Poultry Science, 14, 276-278.2015. https://doi.org/ 10.3923/ijps.2015.276.278

Arturo Anadón; Irma Ares; Maria Rosa Martínez-Larrañaga; Maria Aŕanzazu Martínez (2019): Prebiotics and Probiotics in Feed and Animal Health. Nutraceuticals in Veterinary Medicine VetBoo.2019.https://doi.org/10.1007/97 8-3-030-046248

Bharavi, K.; GopalaReddy, A.; Rao, G.S.; Ravikumar, P.; Rajasekhar Reddy, A. and Rama Rao, S.V. (2010): Reversal of cadmium induced oxidative stress and its bio-accumulation by culinary herbs Murraya koenigii and Allium sativum. Res. J. Pharmacol., 4: 60-65.2010 https://doi.org/10.3923/rjpharm.2010.60. 65

Bozkurt, M.; Alcicek, A.; Çabuk, M.; Kucukyilmaz, K. and Çatli, AU. (2009): Effect of an herbal essential oil mixture on growth, laying traits, and egg hatching characteristics of broiler breeders. Poultry Sci., 88: 23682374.2009. https://doi.org/10.3382/ ps.2009-00048

Calik A. Ergün (2015): Effect of lactulose supplementation on growth performance, intestinal histomorphology, cecal microbial population, and short-chain fatty acid composition of broiler chickens. Poult Sci 94(9):2173-2182.2015. https://doi. org/10.3382/ps/pev182

Chaucheyras-Durand, $F$. and Durand, $H$. (2010): Probiotics in animal nutrition and health. Benef Microbes 1(1): 3 . 2010.https://doi.org/10.3920/bm2008.10 $\underline{02}$

Cheng, G.; Hao, H.; Xie, S.; Wang, X.; dai, M.; Huang, L. and Yuan, Z. (2014): Anti biotic alternatives: the substitution of antibiotics in animal husbandry? Frontiers in Microbiology 5: 217. 
Cho, J.H.; Kim, H.J. and Kim, I.H. (2014): Effects of phytogenic feed additive on growth performance, digestibility, blood metabolites, intestinal microbiota, meat color and relative organ weight after oral challenge with Clostridium perfringens in broilers. Livest. Sci., 160: 8288.2014. https://doi.org/10.1016/j.livsci. 2013.11.006

Choct, M. (2006): Enzymes for feed industry. Past, present and future. World's Poultry Science Journal. 62: 5-15.2006 https://doi.org/10.1079/wps200480

Corrigan, A.; De Leeuw, M.; Penaud-Frezet, S. and Dimova, D. (2015): Murphy RA. Phylogenetic and functional alterations in bacterial community compositions in broiler ceca as a result of mannan oligosaccharide supplementation. Appl Environ Microbiol.81:3460-70.2015. Doi:10. 1128/AEM.04194-14

Cowieson, A.J. and Singh, DH. (2006): Adeeola Prediction of ingredient quality and the effect of a combination of xylanase, amylase, protease and phytase in the diets of broiler chicks. Growth performance and digestible nutint intake. British Poultry Science.47:477489.2006. https://doi.org/10.1080/ 00071660600830603

Cowieson, AJ.; Bedford, MR. and Ravindran, $V$. (2010): Interactions between xylanase and glucanase in maize-soy-baseddiets for broilers. Brit. Poult. Sci. 51:246-257. 2010.https://doi.org/ $10.1080 /$ 00071661003789347

Daniel Hernandez-Patlan; Bruno Solis-Criz; Bill M. Hargis and Guillermo Tellez (2019): The use of probiotic in poultry production for the control of bacterial infection and aflatoxins. Potential Benefits in Nutrition and Health. Doi:10.5772/intechopen.88817.

Dhama, K.; Latheef, S.K.; Mani, S.; Samad, H.A.; Kartik, K.; Tiwari, R.; Khan, R.U.; Al-Agawany, M.; Farag, M.R.; Alam, G.M. and Laudadio, $V$. and Tufarelli V. (2015): Multiple beneficial applications and modes of action of herbs in poultry health and production A review. Int. J. Pharmacol., 11: 152-
176.2015. https://doi.org/10.3923/ ijp.2015.152.176

Dierick, N.A. and Decuypere, J.A. (2004): Influence of lipase and or emulsifier addition on the ileal and faecal nutrient digestibility in growing pigs fed diets containing animal fat. Journal of the Science of Food and Agriculture. 84(12):1443-1450.2004. https://doi.org/10.1002/jsfa.1794

Elijah Kiarie1, Luis FRomerol, Charles M. and Nyachoti (2013): The role of added feed enzymes in promoting gut health in swine and poultry. Nutrition Research Reviews. 26, 71-88.2013. doi:10.1017/ S0954422413000048.

Emami Khodambashi, N.; Samie, A.; Rahmani, H.R.; Ruiz-Feria, C.A. (2012): The effect of peppermint essential oil and fructooligosaccharides, as alternatives to virginiamycin, on growth performance, digestibility, gut morphology and immune response of male broilers. Anim. Feed Sci. Technol., 175: 57-64.2012. $\quad$ https://doi.org/ 10.1016/j.anifeedsci.2012.04.001

European Food Safety Authority (EFSA): Opinion of the Panel on additives and products or substances used in animal feed (FEEDAP) for the establishment of guidelines on the assessment of safety and efficacy of silage additives, on a request from the Commission under Article7(5)ofRegulation(EC)No1831/20 03.JournalArticle published in EFSA.Jo urnal 4 (4).2006 https://doi.org/10.2903/j.efsa.2006.349

Gerhard Flachowsky (2018): Influence of Feed from Genetically Modified Plants on the Composition and Quality of Foods of Animal Origin. Genetically Engineered Foods. Handbook of Food Bioengineering

Gibson, GR. and Hutkins, R. (2017): Sanders, ME. The International Scientific Association for Probiotics and Prebiotics (ISAPP) consensus statement on the definition and scope of prebiotics. Nat Rev Gastroenterol Hepatol 14: 491502.2017. nrgastro.2017.75.

$G u, X$. and Li, D. (2003): Fat nutrition and metabolism in pig lets: A review. Anim. 
Feed. Sci. Technol.109:151-170.2003. https://doi.org/10.1016/s0377-8401 (03)00171-8

Hameed, H.M.; Tawfeek, F.K. and AdulRhaman, S.Y. (2020): Effect of $\beta$ mannanase, Lysolecithin and probiotic on some reproductive performance and hormone profile in female quail. Iraqi Journal of Veterinary Sciences. (34)1: 87-93. https://doi.org/ 10.33899/ijvs.2019.125587.1097

Hardy, GA.; Sieg, S. and Rodriguez, B. (2013): Interferon- $\alpha$ is the primary plasma type-I IFN in HIV-1 infection and correlates with immune activation and disease markers. PLoS One 8(2):e56527.2013. https://doi.org/ 10.1371/journal.pone.0056527

Hill, B.C.; Guarner, F.; Reid, G.; Gibson, GR.; Merenstein, DJ. and Pot, B. (2014): Expert consensus document: The International Scientific Association for Probiotics and Prebiotics consensus statement on the scope and appropriate use of the term probiotic. Nature reviews. Gastroenterology. 2014. https://doi.org/10.1038/nrgastro.2014.66

Hosseini, SM. and Afshar, M. (2016): Effects of feed form and xylanase supplementation on performance and ileal nutrients digestibility of heatstressed broilers fed wheat-soybean diet. J Appl Poult Res. 45:550.556. 2007.https://doi.org/10.1080/09712119. 2016. 1224765.

Iqbal, J. and Hussain, M.M. (2009): Intestinal and lipid absorption. Am. J. Physiol. Endocrinol. Metab. 296: E1183-E1194. 2009. https://doi.org/10.1152/ajpendo.9 0899.2008

Jackson, M.E.; Geronian, K.; Knot, A.; Mcnab, J. and Mccartney, E.A. (2004): dose response study with the feed enzyme beta-mannanase in broiler provided with corn-soy bean meal based diets in the absence of antibiotic growth promoters. Poultry Science. 83: 1992 1996.2004. $\quad$ https://doi.org/10.1093 /ps/83.12.1992

Jang, I.S.; Ko, Y.; Kang, YS. and Lee, CY. (2007): Effect of a commercial essential oil on growth performance, digestive enzyme activity and intestinal microflora population in broiler chickens. Animal Feed Science and Technology 134(3): $\quad$ 304-315.2007. DOI: 10.1016/j.anifeedsci.2006.06.009

Jatinder Singh and Dhananjay Suresh Gaikwad (2020): Phytogenic Feed Additives in Animal Nutrition Book Chapter published 2020 in Natural

Bioactive Products in Sustainable Agriculture on pages 273 to 289. https:// doi.org/10.1007/978-981-15-3024-1_13

Kalantar Majid and Mohammad Hassan Kalantar (2017): Effects of Different Source of Dietary Non-Starch Polysaccharides on Growth Performance, Physiological Characteristics and Gene Expression of GLUT2 in Chickens. Journal Article published Jan 2017 in International Journal of Pharmacology, Photochemistry and Ethnomedicine volume 6: 21- 29. 2017. https://doi.org /10.18052/www.scipress.com/ijppe.6.21

Kamran, J.; Mehmood, S.A. and Mahmud Saima (2020): Effect of Fat Sources and Emulsifier Levels in Broiler Diets on Performance, Nutrient Digestibility, and Carcass Parameters. Braz. J. Poult. Sci. vol.22 no.1 Campinas 2020 Epub Ju ne 05, 2020. http://dx.doi.org/10.1590/ 1806-9061-2019-1158

Khan, N.; Vidyarthi, A. and Pahari, S. (2016): Signaling through NOD-2 and TLR-4 bolsters the $\mathrm{T}$ cell priming capability of dendritic cells by inducing autophagy. Sci Rep 6:19084.2016. https://doi.org/ 10.1038/srep19084

Kiczorowska, B.; Samolińska, W.; Al-Yasiry, ARM. and Kowalczyk-Pcka, D. (2016): Effect of supplementation of mixtures for broiler chickens with Boswellia serrata on the condition of the gastrointestinal tract and rearing efficiency. Ann Anim Sci 16: 1-15. 2016. https://doi.org/10.1515/aoas-2016$\underline{0007}$

Kim, S.A.; Kim, M.J.; Jang, S.Y.; Kim, Y. and Yang, H.O. (2019): Pavlidis, S.C. Ricke. Potential for prebiotics as feed additives to limit foodborne Campylobacter establishment in the poultry gastrointestinal tract Front. 
Microbiol., (10). 91.2019.doi: 10.3389/ fmicb.2019.00091.

Kim, YS.; Hwang, JW.; Sung, SH.; Jeon, YJ.; Jeong, JH.; Jeon, BT.; Moon SH. and Park PJ.(2015): Antioxidant activity and protective effect of extract of Celosia cristata $\mathrm{L}$. flower on tert-butyl hydroperoxide-induced oxidative hepatotoxicity. Food Chem., 68: 572579.2015. https://doi.org/10.1016/ j.foodchem.2014.07.106

Labaque, MC.; Kembro, JM.; Luna, A. and Marin, RH. (2013): Effects of thymol feed supplementation on female Japanese quail (Coturnix coturnix) behavioral fear response. Anim. Feed Sci.Technol., 183: 67-72.2013.https:// doi.org/10.1016/j.anifeedsci.2013.04.01 $\underline{8}$

Lan, Y. and Verstegen, MWA. (2005): Tamminga S, Williams BA. The role of the commensal gut microbial community in broiler chickens. Worlds Poult Sci J. 61: 95-104.2005. Doi10.1079/WPS200445

Lavelle, EC.; Murphy, C.; O'Neill, LA. and Creagh, EM. (2010): The role of TLRs, NLRs, and RLRs in mucosal innate immunity and homeostasis. Mucosal Immunol. 3: 17-28.2010. Doi: 10.1038/mi.2009.124

Maty, HN. and Hassan, AA. (2020): Effect of supplementation of encapsulated organic acid and essential oil Gallant+ ${ }^{\circledR}$ on some physiological parameters of Japanese quails. Iraqi Journal of Veterinary Sciences, Vol. 34, No. 1, 2020 (181-188).2019. DOI: 10.33899/ ijvs.2020.126580.1344

Meng, X.; Slominski BA.; Nyachoti, GM.; Campbell, L.D. and Guenter, W. (2005): Degradati, on of cell wall polysaccharides by combinations of carbohydrates enzyme and their effect on nutrient utilization and broiler chicken performance. Poultry Science. 84. 37-47.2005. https://doi.org/10.1093 /ps/84.1.37

Muhammad S.; Anjum A. and Abdul S. Chaudhry (2010): Using enzyme and organic acid in broiler diets.j.Poult.Sci., 47: 97-105.2010 doi: . /jpsa 009082.
Nagpal, R. and Kaur, A. (2011): Synbiotic effects of various prebiotics on in vitro activities of probiotic lactobacilli. Ecol Food Nutr 50 (1): 63-68.2011. https://doi.org/10.1080/03670244.2011. 539161

Nisha, AR. (2008): Antibiotic residues: A global health hazard. Vet World. 1 (12): 375-377. 2008. https://doi.org/10.5455 /vetworld.2008.375-377

Pineiro, Maya; Nils-Georg, Reid; Gregor, Macfarlane, Sandra and Morelli, Lorenzo. (2008): FAO Technical Meeting on Prebiotics. Journal of Clinical Gastroenterology: 2008 - 42 S156-S159.2008.doi: 10.1097/MCG. 0b013e31817f184e

Pourabedin M. Zhao (2015): Prebiotics and gut microbiota in chickens. FEMS Microbiol Lett 362:fnv122.2015. https://doi.org/10.1093/femsle/fnv122

Pourreza, J.; Samie, AH. and Rowghani, E. (2007): Effect of supplemental enzyme on nutrient digestibility and performance of broiler chicks fed on diets containing triticale. Int. J Poult Sci.6: 115117.2007. https://doi.org/10.3923/ijps. 2007.115.117

Rajani, J.; Dastar, B.; Samadi, F.; Karimi Torshizi, MA.; Abdulkhani, A. and Esfandyarpour S. (2016): Effect of extracted galactoglucomannan oligosaccharides from pine wood (Pinus brutia) on Salmonella typhimurium colonisation, growth performance and intestinal morphology in broiler chicks. Br Poult Sci. 57: 682-92.2016 Doi:10.1080/00071668.2016.120001

Ran, T.; Gomaa, W.M.S., Shen, Y.Z.; Saleem, A.M.; Yang, W.Z. and McAllister, T.A. (2019): Use of naturally sourced feed additives (lactobacillus fermentation products and enzymes) in growing and finishing steers: Effects on performance, carcass characteristics and blood metabolites. Animal Feed Science and Technology, 254, 114190.2019 https://doi.org/10.1016/j.anifeedsci.2019 .05 .013

Ravindran, V.; Tancharoenrat, P.; Zaefarian, F. and Ravindran, G. (2016): In poultry nutrition: digestive physiology and factors influencing their utilization. 
Animal Feed and Science and Technology. 13457: 21. 2016 https://doi.org/10.1016/j.anifeedsci.2016 .01 .012

Roberfroid, M.; Gibson, GR. and Hoyles, L. (2010): Prebiotic effects: metabolic and health benefits. Br J Nutr 104(2):S1S63.2010. https://doi.org/10.1017/ s0007114510003363

Roy, A.; Haldar, S.; Mondal, S. and Ghosh, K. (2010): Effect of supplemental exogenous emulsifier on performance, nutrient metabolism and serum lipid profile in broiler chickens. Veterinary Medicine International 10: 1-9.2010. https://doi.org/10.4061/2010/262604

Saad, N.; Delattre, C. and Urdaci, M. (2013): An overview of the last advances in probiotic and prebiotic field. LWT Food Sci Technol 50:1-16.2013. https://doi.org/10.1016/j.1wt.2012.05.01 $\underline{4}$

Safa Mohamed, A. and Wahab El-Tazi (2014): Response of Broiler Chicken to Diets Containing Different Mixture Powder Levels of Red Pepper and Black Pepper as Natural Feed Additive. Animal and Veterinary Sciences. 2(3): 81-86. 2014. https://doi.org/10.11648/j.avs.20140203. $\underline{15}$

Siyal, FA.; Babazadeh, D.; Wang, C.; Arain, MA.; Saeed, M.; Ayasan, T.; Zhang, L.and T. Wang, (2017): Emulsifiers in the poultry industry. World's Poultry Science Journal. 73.2017. doi:10.1017/S0043933917000502

Sohail, M.U.; Ijaz, A.; Yousaf, MS.; Ashraf, K.; Zaneb, H.; Aleem, M. and Rehman (2010): Alleviation of cyclic heat stress in broilers by dietary supplementation of mannan-oligosaccharide and Lactobacillus based probiotic, dynamics of cortisol, thyroid hormones, cholesterol, C-reactive protein, and humoral immunity. Poultry Science, 89, 1934- 1938.2010.https://doi.org/ 10.3382/ps.2010-00751

Stanley, D.; Denman, SE. and Hughes, RJ. (2012): Intestinal microbiota associated with differential feed conversion efficiency in chickens. Appl Microbiol Biotechnol 96:1361-1369.2012. https:// doi.org/10.1007/s00253-011-3847-5
Tancharoenrat, P.; Ravindran, V.; Zaefarian, F. and Ravindran, G. (2013): Influence of age on the apparent metabolisable energy and total tract apparent fat digestibility of different fat sources for broiler chickens. Anim. Feed Sci. Technol. 186(3-4): 186-192. 2013. https://doi.org/10.1016/j.anifeedsci.2013 .10 .013 .

Taylor-Pickard, JA. and Spring, P. (2008): Gut efficiency; the key ingredient in pig and poultry production Book published 28 Jan 2008. https:// doi.org/10.3920/978-90-8686-636-6

Teng, Kim PL, Teng W.K, Kim. (2018): Review: roles of prebiotics in intestinal ecosystem of broilers Front.Vet Sci. 5: 245. 2018.doi: 10.3389/fvets. 2018.00245

Upadhaya, S, Park, J, Yun, H. and Kim, I. (2018): Role of emulsifier as fat replacer in low density diet for growing and finishing pigs. J. Anim. Sci. 94(2): 133133.2018 https://doi.org/10.2527/ msasas2016-283

Upadhaya, SD.; Kim, SJ. and Kim, IH. (2016): Effects of gel-based phytogenic feed supplement on growth performance, nutrient digestibility, blood characteristics and intestinal morphology in weanling pigs. J. Appl. Anim. Res., 44: 384-389.2016. https://doi.org/10.1080/09712119.2015. 1091334

Upadhaya, SD.; Lee, JS.; Jung, KJ. and Kim, IH. (2018): Influence of emulsifier blends having different hydrophiliclipophilic balance value on growth performance, nutrient digestibility, serum lipid profiles, and meat quality of broilers. Poult. Sci. 2018; 97(1):255261. https://doi.org/10.3382/ps/pex303

Windisch, WM.; Schedle, K.; Plitzner, C. and Kroismayr, A. (2007): Use of phytogenic products as feed additives for swine and poultry J Anim Sci.86: 140-148.2008 https://doi.org/10.2527/ jas.2007-0459

Yegani, M. and Korver, DG. (2013): Effects of corn source and exogenous enzymes on growth performance and nutrient digestibility in broiler chickens. Poultry 
Science. 92(5):1208-1220.2013. https://doi.org/10.3382/ps.2012-02390.

Yitbarek, A.; Echeverry, H.; Munyaka, P. and Rodriguez Lecompte, JC. (2015): Innate immune response of pullets fed diets supplemented with prebiotics and synbiotics. Poultry $\quad$ Science 94: 18021811 .

Zaefarian, F.; Romero, LF. and Ravindran, $V$. (2015): Influence of high dose of phytase and an emulsifier on performance, apparent metabolisable energy and nitrogen retention in broilers fed on diets containing soy oil or tallow. $\mathrm{Br}$ Poult Sci 2015; 56(5): 590597. https://doi.org/10.1080/00071668. 2015.1067878

Zeng, Q.; Huang, X.; Luo, Y.; Ding, X.; Bai, S.; Wang, J.; Xuan, Y.; Su, Z.; Liu, Y. and Zhang, $K$. (2015): Effects of a multi-enzyme complex on growth performance, nutrient utilization and bone mineralization of meat duck. J Anim Sci Biotechnol.6:12.2015. https://doi.org/10.1186/s40104-0150013-4

Zhang, MM.; Cheng, JQ.; Lu, YR.; Yi, ZH.; Yang, $P$. and $W u, X T$. (2010): Use of pre-, pro-and synbiotics in patients with acute pancreatitis: a metaanalysis. World J Gastroenterol: WJG. 16(31): 3970.2010.doi: 10.3748/wjg. v16.i31.3970.

Zhao, P.; Li, H. Hossain, M. and Kim, I. (2015): Effect of emulsifier (lysophospholipids) on growth performance, nutrient digestibility and blood profile in weanling pigs. Anim. Feed Sci. Technol. 207: 190195.2015 https://doi.org/10.1016/j.anife edsci.2015.06.007 109-141

\section{الاضافات العلقية في الاواجن}

\section{هديل محمد حمبي \\ فرع الفسلجة و الكيمباء الحياتية والادوية , كلية الطب البيطري ,جامعة الموصل ,العر اق}

E-mail: dochadeel1979@gmail.com Assiut University web-site: www.aun.edu.eg

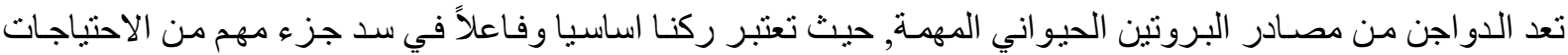

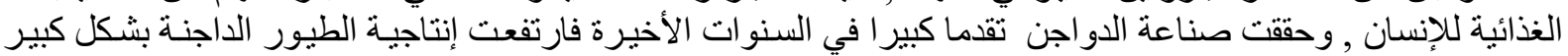

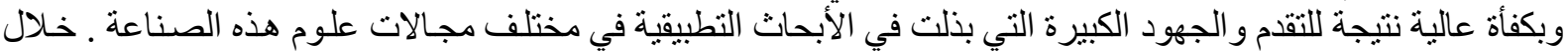

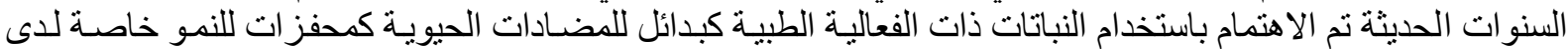

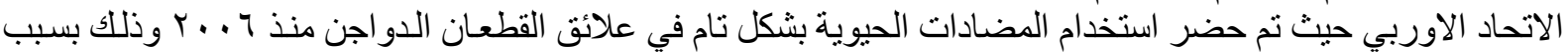

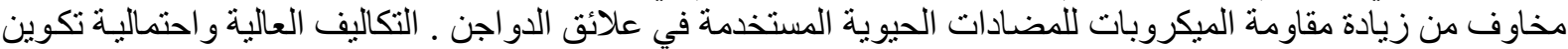

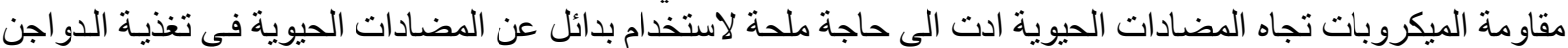

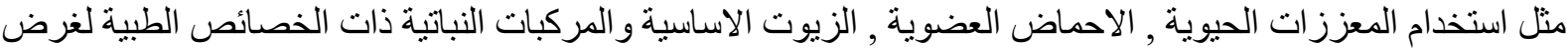

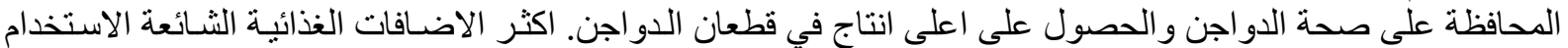

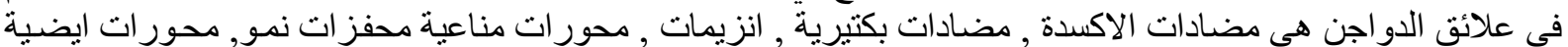

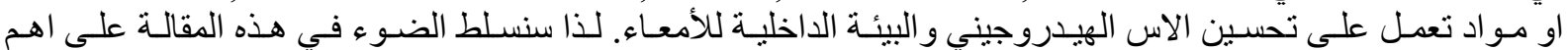

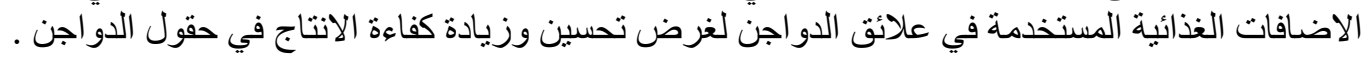

$$
\text { الكلمات المفتاحية : الاضافات العلفية , المركبات النباتية , الدواجن , المضادات الحيوية }
$$

